\title{
A GEOGRAFIA POLÍTICA a propósito dos escritos de Friedrich Ratzel ${ }^{*}$
}

\author{
PAUL VIDAL DE LA BLACHE
}

Muitas vezes os leitores desta revista tiveram chamada a sua atenção para os trabalhos do Sr. Friedrich Ratzel. Quando publicada a segunda parte da Antropogeografia, a importância e a originalidade desta obra foram apreciadas por um de nossos colaboradores em um estudo que é importante relembrar ${ }^{1}$. Desde esta época, a atividade do Sr. Ratzel continuou a se desenvolver neste mesmo sentido. O último recenseamento dos Estados-Unidos ofereceu-lhe a oportunidade de reescrever num volume inteiramente novo o panorama de geografia política anteriormente descrito em sua obra marcante sobre os Estados Unidos da América ${ }^{2}$. Surgiu depois uma nova edição, revista, de sua Etnografia ${ }^{3}$. Eis aqui, agora, sob o título de Geografia Política, uma nova publicação, na qual o autor procura, por uma aplicação especial ao estudo dos Estados, concentrar e precisar sua doutrina ${ }^{4}$. Se acrescentarmos que o eminente professor de geografia da Universidade de Leipzig reúne em torno de sua cadeira alunos que publicam monografias especiais diretamente inspiradas no espírito de seu mestre ${ }^{5}$, percebemos qual é a atividade deste ateliê de trabalho, que deve ainda mais ser destacada pelo fato de representar tendências que se tornam raras, hoje, na vida universitária da Alemanha.

Enquanto a geografia física de fato atrai para si uma legião crescente de pesquisadores, é preciso convir que, neste último quarto de século, a geografia política foi menos favorecida. Ela viveu durante muito tempo da impulsão fecunda que lhe havia dado Carl Ritter, mestre ao qual a Alemanha é devedora do avanço adquirido pelas publicações de geografia e de cartografia políticas. Mas os tempos passaram e este ramo da ciência não atingiu o nível de progresso alcançado no seu entorno. De nossa parte, cremos firmemente que, em definitivo, nada seria mais fecundo para a geografia política que o desenvolvimento tão marcante que alcança, sob nossos olhos, o estudo físico do globo. As relações entre o homem e o meio no qual se exerce sua atividade não podem deixar de se revelar mais claramente à medida que hesitarmos menos através do estudo das formas, dos climas e da repartição da vida. Mas ainda é preciso que um trabalho de aproximação intervenha entre estas ordens de estudo. Seria em vão confiarmos esta tarefa ao acaso ou ao tempo. Ao contrário, o momento sem dúvida parece ter chegado, e a iniciativa

* In: Annales de Géographie n. 32, ano 7, 15 de março de 1898 (título original: La Géographie Politique a propos des écrits de M. Frédéric Ratzel). Tradução: Rogério Haesbaert e Sylvain Souchaud.

1 L. RAVENEAU, L'élément humain dans la Géographie. L'Anthropogéographie de M. Ratzel (Ann. De Géog., I, 1891-1892, p. 331-347). O primeiro volume (506 p.) foi lançado em 1882, o segundo (781 p.) em 1891.

2 Die Vereiningten Staaten von Amerika (2 vol.). I. Physikalische Geographie und Naturcharakter (667 p., 1878). II. Politische Geographie (2. Auflage, 1893). 763 p. Munique e Leipzig, R. Oldendburg. Völkerkunde (2. Auflage), Vol. 1, 748 p. (1894). Vol. 2, 779 p. (1895).

Politische Geographie, 1 vol. 715 p. (1897). Munique e Leipzig, R. Oldenburg.

Alguns desses trabalhos foram reunidos em um volume, publicado sob os auspícios da Sociedade de Geografia de Leipzig: Anthropogeographische Beiträge, Leipzig, Duncker e Humblot, 1895 (10 mapas). Além desta publicação, citaremos ainda, pelo interesse especial que a região representa para nós, o consciente estudo publicado pelo Sr. Dr. Paul Constantin Meyer sobre o Sudão Ocidental, Erforschungsgeschichte und Staatendbildungen des West Sudans (Peterm. Mitt. Eryzh., n. 121). 
perseverante do Sr. Ratzel põe em foco uma carência que começa a preocupar todo mundo. "De novo, diz ele, ouve-se o ressoar das queixas sobre a frieza da geografia política, queixas tão antigas quanto o ensino da geografia" .

Essas queixas são do mesmo tipo daquelas que também conhecemos na França. Se elas são fundadas, provam que as obras de geografia política às quais se aplicam não se inspiram em uma concepção clara do objeto da ciência. As razões são diversas. Mas a principal é exatamente aquela que o Sr. Ratzel indica: os fatos da geografia política encontram-se ainda muito esparsos, sem adaptação àqueles da geografia física. É este trabalho de agrupamento e de coordenação que o Sr. Ratzel tentou alcançar nos diferentes estudos que citamos, pois não é homem de se contentar em formular críticas e esboçar programas. Esta preocupação comum fornece a unidade de seus trabalhos. Ele procura agrupar os fatos e extrair leis, a fim de colocar à disposição da geografia política um fundo de idéias sobre o qual ela possa viver.

A riqueza do tema explica a abundância de desenvolvimentos. Quando se lêem esses volumes, impregnados de muita substância, o espírito pode provar algumas hesitações diante de proposições que parecem apresentar uma forma dogmática com pouca relação com a relatividade dos fenômenos. Mas é surpreendente este tesouro de observações e de fatos. Certamente a geografia política pode amplamente tirar proveito deles. Entretanto, só terá proveito à medida que ela própria se definir, o que não pode fazer senão tornando precisa a natureza da relação que a une ao conjunto da geografia. Desta relação depende o método a ser seguido, em particular o discernimento a ser praticado entre os fatos que ela deve reivindicar como seu patrimônio, e aqueles que ela deve eliminar como parasitas. Uma certa hesitação ainda reina, no ensino e alhures, sobre as atribuições da geografia política, sobre a definição de seu domínio: sobretudo porque não se percebe claramente qual lugar lhe pertence entre as diferentes ciências que têm por objeto comum decifrar a fisionomia da Terra.

\section{A posição da Geografia Política na Geografia}

Os historiadores que se preocuparam em destacar as influências geográficas obedeceram, sobretudo, à idéia de que estas influências, muito fortes ou mesmo preponderantes no início, enfraqueciam-se em seguida, ao ponto de se tomarem, para muitos deles, negligenciáveis. Este ponto de vista não deveria ser o do geógrafo. Seguramente, a emancipação pela qual o homem pouco a pouco se liberta do jugo das condições locais, é uma das lições mais instrutivas que nos proporciona a história. Mas, civilizado ou selvagem, ativo ou passivo, ou, sobretudo, sempre, ao mesmo tempo um e outro, o homem, nestes diferentes estados, não deixa de fazer parte integrante da fisionomia geográfica do globo. Através dos estabelecimentos que ele constrói na superfície do solo, pela ação que exerce sobre os rios, sobre as próprias formas do relevo, sobre a flora, a fauna e todo o equilíbrio do mundo vivente, ele pertence à geografia, onde joga um papel de causa. Ainda que a habitabilidade não cubra inteiramente o globo, pode-se dizer que, nas raras regiões em que ele não penetra, a ação preponderante que exerce sobre o mundo da vida não deixa, em certa medida, de se fazer sentir. A superabundância da vida animal que encontra refúgio em uma parte das regiões polares é ainda um indício indireto da sua presença.

6 A geografia política constitui, em sentido estrito, um desenvolvimento especial da geografia humana. E assim que parece entender o Sr. Ratzel. Mas, nas aplicações da geografia ao homem, trata-se sempre do homem por sociedades ou por grupos, de modo que se pode crer autorizado a dar ao nome de geografia política um sentido mais amplo, e estendê-lo ao conjunto da geografia humana. 
À medida que intervém esta força sutil e flexível chamada atividade humana ${ }^{7}$, um princípio novo de antagonismo é introduzido nos fenômenos terrestres, perturbando profundamente a economia e modificando o seu aspecto. Não é mais o conflito mecânico entre as formas do relevo e as leis da gravidade, nem a luta pela qual os vegetais disputam entre si um lugar sobre o solo ou em relação à luz: o espetáculo exterior das coisas se revela tão logo uma força de espécie diferente entra em luta. Porque é bem mais como ser dotado de iniciativa que como ser sofrendo passivamente as influências exteriores que o homem possui um papel geográfico. A montanha oferece-lhe um meio de evitar o ataque de seus inimigos, ou, em certos casos, de livrar-se dos perigos do clima; o rio, uma via de circulação; a ilha, um refúgio ou um ponto de apoio mais cômodo da atividade comercial. Mas, ao mesmo tempo em que o atrai por diferentes razões, cada uma dessas formas terrestres revela sua engenhosidade com as necessidades especiais de existência.

Graças a esta flexibilidade e a uma vitalidade que se adapta a todos os climas, há muito poucas partes da superfície terrestre às quais não se incorpora a fisionomia humana. Sua imagem se associa às formas mais diversas de configuração e de relevo. Por pouco que nos afastemos um instante dos cenários de natureza humanizada que nos são familiares, o vazio nos chama a atenção.

A primeira aldeia que percebemos, depois de algumas horas passadas na montanha, ao atravessarmos alguma passagem estreita, modesto traço do homem, mas signo visível de que aí recomeça sua ação direta e contínua sobre as coisas, responde a um sentimento instintivo de previsão; ela nos dá esta impressão pessoal de vida que para nós é inseparável da imagem das regiões ${ }^{8}$.

Os Alpes nos mostram este esforço pessoal para resolver o problema da existência em altitudes elevadas. O montanhês capta as orientações favoráveis, acomoda suas culturas às vertentes sobre as quais perduram os raios do sol, ajusta a irrigação das encostas, agrupa suas habitações sobre os taludes protegidos contra as torrentes. Sobre as encostas do Pamir, o montanhês tadjique do Darvaz e do Chignan ${ }^{9}$ mostra igual engenhosidade e emprega os mesmos métodos de aproveitamento de suas montanhas. Os flancos arqueados dos montes do Vivarais são de alguma forma esculpidos pelos muros de pedra que sustentam as culturas em terraços, obra secular na qual se resume o trabalho paciente de gerações dos nossos camponeses. Sobre as vertentes dos vulcões de Java, até a altitude de cerca de 1500 metros, vemos escalonarem-se as mesmas culturas em terraço.

Existe o que podemos denominar uma via fluvial, muito diferente, sem dúvida, segundo o grau de civilização dos ribeirinhos, mas também adequada como objeto de estudo tanto sobre as margens do Congo e do Ubangui quanto dos rios da Europa e da China. Em todo lugar trata-se, para o homem, de levar em conta o regime, os ritmos e, de alguma forma, todas as palpitações deste ser caprichoso que é o rio, a fim de, com vantagens e a menor soma possível de perigos, unir a sua vida à vida do rio. A cidade se mantém freqüentemente à distância, sobre algum terraço ou margem elevada, ao abrigo de seus caprichos. Sobre a margem dos rios russos, que sofrem inundações periódicas na primavera, a exploração das pradarias é regulada de acordo com este regime: quando os camponeses russos da província do Amur se viram em presença de um rio de

7 “A humanidade, afirma muito bem o Sr. Ratzel, é um todo, apesar dos diversos graus de civilização". ( Völkerkunde, cap. 1, p. 4)

8 N.T.: como em outros momentos em que é utilizado neste texto o termo "região", trata-se da palavra francesa "contrée", que algumas vezes é traduzida, de forma mais apropriada, por área ou zona.

9 A . Regel, Die einheimischen und angebauten Kulturpflanzen des obern Amu-Daria (1883). 
cheias periódicas de verão, isto lhes custou, como mostrou recentemente aqui o Sr. Woeikof, não terem sabido modificar, em conseqüência, as épocas de fenação e suas práticas agrícolas.

Os fenômenos da geografia política se modificam segundo as condições de extensão e de isolamento das áreas que são seu teatro. As ilhas, os oásis, apresentam particularidades na geografia dos homens que correspondem às particularidades existentes na sua configuração e na sua posição. Se o isolamento for grande, as localidades envolvidas pelo mar ou pelo deserto são capazes de conservar populações que em outros lugares desapareceram - é o caso dos Guanches nas ilhas Canárias ou dos etíopes trogloditas que Nachtigal descobriu, há vinte anos, sob o nome de Tedas, nas solidões centrais do Saara. Quando o espaço assim delimitado é reduzido, a densidade de população, com freqüência, alcança um nível pletórico, produzindo hábitos de emigração. Disso decorre que, nas correntes que sustentam o intercâmbio entre áreas distintas, o papel das populações insulares é, e sempre foi, muito marcante. As ilhas do arquipélago grego promovem migrações por todo o Oriente do Mediterrâneo. O rochedo de Malta dispersa seus emigrantes pela África. Insulares dos Açores trabalham nas plantações de cana-de-açúcar do arquipélago das Sandwich, os das Canárias na Venezuela, etc. É natural que, nas ilhas, o litoral, único ponto de partida de relações exteriores, adquira uma importância especial; aí, de fato, situam-se as principais cidades. E o caso de grandes ilhas como a Córsega e a Sicília. A própria Irlanda confirma a observação. Madagascar permaneceu, do ponto de vista político, um pequeno continente: a colonização européia, sem dúvida, irá desenvolver aí o caráter insular e fará afluir a vida sobre o seu litoral.

Entre a geografia física e a geografia política o anel intermediário é o estudo geográfico das plantas. E a planta que retira do mundo inorgânico os elementos da nutrição que ela elabora para o animal, e que este seria incapaz de conseguir diretamente. Ela é, assim, o intermediário entre os dois principais ciclos de fenômenos geográficos, os do mundo inanimado e os do mundo vivente. Através dos elementos nutritivos que obtém da atmosfera, e que somente ela pode decompor, a vegetação é como uma fábrica viva de alimentos. A manutenção da população animal, enquanto carnívora, está em relação com os recursos vegetais da sua área.

Assim, entre o homem e o restante da natureza viva estabelece-se uma solidariedade que é possível estudar sob a forma mais simples nas zonas circumpolares, onde a manutenção de uma população humana se encontra sob a dependência estreita do mundo animal. Podemos dizer que se a própria rena não encontrasse uma espécie de líquen que lhe permite atravessar o inverno, a existência do homem, seu companheiro, seria impossível.

Mas essa solidariedade se aplica com um alcance bem diferente no estudo geográfico das grandes sociedades humanas. Entre as duas formas quase igualmente hostis da floresta equatorial e da floresta boreal, as regiões que ofereceram ao homem as condições mais favoráveis para o estabelecimento de grupos organizados em grande escala são as planícies ensolaradas e campestres. Crescem aí as principais gramíneas próprias a se tornarem meio de alimentação para numerosos animais e para o próprio homem. Savanas ou pradarias foram as partes da Terra em que se produziu uma combinação capital na história da humanidade, aquela da agricultura com a ajuda de animais domésticos para este fim. A persistência que é própria das causas geográficas é mostrada hoje nas concentrações que se formam nas terras negras da Rússia e nas pradarias da América, como um prolongamento do fenômeno e como a imagem do que outrora se passou nas planícies do Punjab, da Caldéia e da China do Norte.

O homem não age de forma diferente das relações com o mundo vivo nas relações com o 
mundo inorgânico. Já vimos, na luta contra a montanha ou o rio, o homem escolher com um tato engenhoso as oportunidades favoráveis a seus propósitos; sobressai-se opondo uma força à outra, entrando no jogo da natureza para neutralizar o que se coloca como obstáculo e apropriando-se do que pode lhe servir. Mas estes procedimentos se exercem no domínio da natureza viva com uma amplitude muito distinta, pois o homem é um agente biológico incomparável. No conflito que as espécies travam entre si para se defenderem contra a invasão de seu espaço por espécies rivais, o homem intervém tomando partido. Mescla-se à batalha para dirigi-la segundo seus próprios fins. Ele somente triunfa sobre a natureza pela estratégia que ela lhe impõe e com as armas que esta lhe fornece. De fato, as condições em virtude das quais algumas espécies dominam e se expandem em uma área não são as de uma apropriação definitiva e absoluta, mas de um equilíbrio que pode ser alterado, e que o será certamente se novos recém-chegados mais vivazes, mais rústicos e mais aguerridos pela concorrência, sobrevenham para disputar lugar. Esta instabilidade de equilíbrio abre ao homem um livre campo para favorecer as espécies que ele entende sejam suas auxiliares ou meios de sua subsistência. Uma de suas plantas favoritas, defendida e fortalecida pela cultura, apropriada por uma escolha inteligente de variedades em condições mais ou menos diversas de solo ou de clima, pode conquistar imensos espaços e passar para o primeiro plano na fisionomia vegetal do globo. $\mathrm{O}$ arroz era uma gramínea que crescia em estado selvagem nos vazios periodicamente submersos deixados pela inundação dos rios tropicais. $\mathrm{O}$ trigo presume-se, vivia em estado selvagem nas planícies descobertas da Ásia ocidental.

Os ventos, as correntes, os rios e os animais têm seu papel na dispersão das espécies. Mas de todos os agentes que dessa forma criam o intercâmbio entre as diversas partes da Terra, que alteram o equilíbrio sempre provisório do mundo animado, nenhum, naturalmente, é comparável ao homem. O europeu moderno, sobretudo, é o artesão infatigável de uma obra que tende a uniformizar, se não o planeta, pelo menos cada uma das zonas do planeta. Os movimentos que o deslocam também movimentam e transportam com ele as plantas e os animais que constituem sua clientela. A Austrália viu, quase sob os nossos olhos, a substituição de sua fauna e flora indígenas por aquelas para lá transportadas pelos europeus. A Nova Zelândia renovou o quadro de sua vida. Durante o período de 1878 a 1889, os Estados Unidos concluíram a conversão de suas pradarias em campos de cultura e, ao mesmo tempo, o bisão, que se contava em tropas de milhões de cabeças, desapareceu quase completamente. A mesma sorte espera em breve o elefante africano. O homem não se desloca sem deixar um rastro na criação vivente. Suas migrações provocam revoluções na fisionomia das regiões. E todo o quadro da vida que muda sobre as superfícies em que uma raça mais avançada em civilização toma lugar.

É por isso que, por sobre os aspectos especiais da geografia botânica, zoológica, política ou humana, há, envolvendo-os todos, o que podemos denominar a geografia da vida. As transformações que o homem realiza na superfície da Terra indicam leis gerais que presidem as diversas manifestações da vida. Levam a modificações que afetam todo o equilíbrio da natureza viva. Combinam-se, enfim, de uma maneira íntima, com as formas terrestres e as condições climáticas. A geografia humana ou política deve assim ser concebida como fazendo parte de um conjunto. Não se trata de um simples capítulo anexo acrescentado a outros, ela mergulha com todas as suas raízes na geografia geral.

\section{Meios e objetos novos de pesquisas}


Não foi sem inconvenientes que a geografia política se desenvolveu antes dos outros ramos da geografia. Ela se ressente das hesitações pelas quais passou. Privada do apoio que teria encontrado no seu entorno, caminhou muitas vezes ao acaso, sem outro guia que o desejo de satisfazer esta curiosidade legítima, mas geral, que sentimos pelas regiões e seus povos. É assim que noções estranhas à geografia muitas vezes a confundiram. Estrabão se dedica de bom grado a dissertações arqueológicas. No século XVI, Sebastião Münster aprecia enriquecer sua Cosmographie, aliás, muito interessante, com pormenores sobre as genealogias das casas reais ou principescas. Hoje, é da invasão inconsiderada de noções de administração ou de estatística que a geografia política é mais ameaçada. Não é o menor dos inconvenientes dessas noções, introduzidas sem considerar o objeto próprio da geografia, expandirem sobre ela um ar de incoerência, que explica o desfavor ou desdém dos quais ela é por vezes objeto.

Se buscarmos quais são os instrumentos novos de investigação e análise que lhe são fornecidos pelos progressos da geografia física e em geral do conhecimento terrestre, temos apenas a dificuldade de escolher entre os exemplos.

Devo passar rapidamente sobre esta parte do assunto sob pena de ampliar demasiadamente este artigo. Mas não é evidente que a geografia política pode obter muito proveito dos mapas topográficos em grande escala? Neles podemos ler o modo de agrupamento da população, fenômeno que apresenta tanta diversidade e nuanças regionais e cujo conhecimento nos indica múltiplos traços característicos e relações entre o homem e o solo. A repartição das aldeias na Champagne seca não se parece com a das campanhas da Picardia. Mais além, o sistema de aglomeração por grupos definidos dá lugar a uma disseminação de aldeias, granjas ou casas, uma espécie de poeira difundida por todo o país. Fatos que dizem muito em relação ao modo de existência dos habitantes. Estas relações se esclarecem, e ao mesmo tempo outras se descobrem, graças aos mapas geológicos em grande escala que agora quase todos os países civilizados possuem. A análise das relações entre o homem e a altitude, a natureza do solo ou a hidrografia, graças a estes instrumentos pode ser apreendida mais de perto. Ela ganharia ainda mais se os mapas geológicos decidissem ser menos sóbrios em termos de indicações sobre os terrenos que formam as camadas superficiais do solo.

Na base da geografia política há uma questão que podemos considerar capital - trata-se da repartição das populações humanas na superfície terrestre. Nada é mais desigual: algumas partes relativamente restritas do globo apresentam enormes aglomerações; a Índia e a China sozinhas compreendem perto da metade da humanidade; são massas humanas cimentadas pelo tempo, contra as quais se exercem as guerras, as epidemias e a fome. Ao contrário, existem vastos espaços novos que o homem, numericamente, mal começou a ocupar. Ora, sobre esses fenômenos que, em conseqüência, influenciam toda a fisionomia geográfica das áreas, apenas começamos a ser informados, desde que censos regulares, ainda em número muito pequeno, permitem comparar em partes distantes o estado e a marcha da população. Foi uma revelação quando, em 1872, o primeiro censo da Índia inglesa nos mostrou, de uma maneira positiva, a existência de perto de 250 milhões de homens (hoje 291) naquela península. Desde 1790, a série monumental de censos decenais dos Estados Unidos da América não pára de fornecer documentos preciosos para seguir o povoamento progressivo de uma vasta região. Podemos assim estudar comparativamente o aspecto geográfico da população em países de antiga civilização, seja na Europa, seja sob os trópicos e nos países novos como a América. Constatamos então fenômenos singulares, alguns dos quais foram trazidos à luz, enfaticamente, pelo Sr. Ratzel. Os Estados 
Unidos contam com algumas das grandes metrópoles do mundo, embora a densidade não atinja 8 habitantes por quilômetro quadrado. A Austrália reúne mais de 30 por cento de sua população em três cidades. As enormes desigualdades de repartição que estas cifras indicam existem até mesmo no raio de ação imediato das grandes cidades. Algumas horas separam Nova York das solidões florestais dos montes Adirondack. Se estivéssemos na Europa, clareiras teriam sido feitas naquelas matas; através de indústrias ou ocupações diversas uma população ter-se-ia engenhado e teria provavelmente conseguido criar ali seus modos de existência: ao contrário, somente alguns lenhadores ou caçadores aventuram-se, e somente no verão, naquelas solidões. Eis assim uma imagem demográfica de país novo.

Por fim, a vasta investigação que há uns cinquenta anos nos faz penetrar no interior dos continentes africano e asiático, teria sido fértil em resultados apenas para a geografia física? Quando Barth trouxe de suas viagens um conhecimento preciso dos Estados muçulmanos que se sucedem do lago Tchad ao Níger, foi o primeiro raio de luz na obscura geografia política do interior africano. Percebemos então um fenômeno que os viajantes posteriores vieram apenas confirmar e estender: a influência do Islã representada pelas raças árabe e berbere sobre a formação de Estados em países negros.

Mas é a Ásia, sobretudo, que se manifestou como aquilo que ela foi em todas as épocas, a terra clássica para o estudo dos fatos da geografia humana. Ao mesmo tempo em que nos oferece o espetáculo de grandes dominações européias penetrando, de lados diferentes, pelo interior do continente, permite-nos observar na sua situação presente os restos das populações que outrora foram, elas próprias, fundadoras de Estados. Encontramos na Ásia Central os vestígios ainda vivos das populações iranianas, tais como foram fragmentadas e afastadas por uma série de invasões mongóis ou turcas, espetáculo instrutivo de uma grande raça política, a qual se pode dizer que foi vítima de sua posição geográfica.

Mal iniciamos o conhecimento das civilizações do Extremo-Oriente. Pouco a pouco, porem, começam a se deixar entrever as bases dessas sociedades cuja evolução foi diferente das nossas. Em vez de nações saídas de uma vasta cristandade que estava organizada ela própria nos quadros preparados pela cidade antiga, encontramo-nos frente a uma multidão de pequenas comunidades de aldeia e de família, inumeráveis células cujo agrupamento forma imensas colméias que se juntam de preferência ao longo dos rios e nas regiões deltaicas. No estudo desse mundo político diferente podemos imaginar que vamos encontrar uma fonte de fenômenos inéditos que também contribuirá para vivificar a geografia política. A separação do elemento agrícola e do elemento pecuário, o antagonismo étnico da planície e da montanha, nos aparecem desde já um dos traços característicos dessas sociedades Orientais.

\section{A classificação e a definição dos fatos}

A geografia política, assim como a geografia física, não pode viver de uma pequena fração da superfície terrestre. Seu campo não se restringe ao espaço que ocupam as sociedades de civilização avançada. Ela não pode acreditar que sua empreitada esteja esgotada pelo estudo de alguns Estados, pontos luminosos em torno dos quais flutuaria, numa vaga penumbra, o resto da humanidade.

Importa-lhe também conhecer estas formas imperfeitas, embrionárias ou rudimentares que marcam, nas relações da terra e do homem, muitos graus diversos, estágios mais ou menos 
avançados. Essas formas de estabelecimentos políticos e de agrupamentos humanos merecem a atenção na medida em que representam os degraus sucessivos que levam a formas mais perfeitas realizadas em algumas partes da Terra. Elas entram na fisionomia política do globo, assim como as árvores de idades diversas e de tamanho desigual concorrem para a composição de uma floresta. Quando Tucídides recompõe o quadro das origens da civilização helênica, ele mostra apenas metade da Grécia saída desse estágio primitivo que representa o agrupamento em aldeias ou povoados, que foi, diz ele, «o antigo costume da Grécia». Somente as áreas da Grécia mais favorecidas pelo solo ou pela posição conseguiram substituir esse estado rudimentar pelo estado mais perfeito que representa a cidade ou pólis ${ }^{10}$. O historiador filósofo expressava assim uma distinção fecunda. Estas primeiras formas de agrupamentos humanos, aldeias, vilarejos, tribos agrupadas ao redor da oppida, são a expressão geográfica de relações locais, demarcadas, limitadas a um só tipo de ocupação e de modo de existência. Muitas frações da humanidade não ultrapassaram esse estágio. Em toda a parte da África que ainda não foi modificada pelas influências européias ou árabes, não existem cidades no verdadeiro sentido da palavra; não se pode dar o nome de cidades a aglomerações de palhoças que não têm, por assim dizer, nem corpo nem alma, nem mesmo a residências ${ }^{11}$ efêmeras de potentados destinados a desaparecer com o capricho que as fez nascer. São criações que ainda não desenvolveram profundas raízes no solo. $\mathrm{O}$ feixe dos diversos ramos de atividade que se concentra na vida normal de um Estado ou de uma cidade não se formou. Se algum comércio exterior se realiza através das pequenas comunidades agrícolas entre as quais se agrupam as populações do centro da África, elas não são por si mesmas os agentes desse comércio; são tribos especiais que muitas vezes desempenham o papel de intermediários entre elas e o mundo exterior.

Nesta hierarquia de formas de agrupamento, a cidade representa num grau de destaque a emancipação do meio local, uma dominação mais forte e mais ampla do homem sobre a terra. A natureza, para isso, sem dúvida, preparou os sítios: nas passagens ou embocaduras dos rios, nas saídas das montanhas, no contato das zonas de climas muito diferentes. Mas é o homem quem cria o organismo. Pelas estradas que ele constrói, faz convergir até o ponto designado relações novas. A incerteza das relações no estado de natureza a cidade substitui por um princípio de estabilidade e continuidade. Ela dá à comunidade política a solidez da pedra com a qual constrói seus monumentos. A afluência dos produtos e a diversidade das formas de trabalho atraem para ela elementos diversos da população que aí se estabelecem. É difícil imaginarmos a possibilidade de que se formem Estados onde já não se encontrem importantes fundações de cidades para fixar, mudar e estender as relações. É sobretudo pelas cidades que se perpetuaram na França as tradições e a língua de Roma. Foi pelas fundações urbanas de Carlos Magno e dos Otons que a Germânia tomou corpo. A cidade é hoje, na América e na Austrália, o signo por excelência da apropriação européía, o núcleo do Estado.

É importante esforçar-se para definir exatamente, com o auxílio de exemplos escolhidos nas realidades atuais, palavras tais como cidades, províncias, limites, Estados, que o vocabulário usual tende a usar indiferentemente. $\mathrm{O}$ sentido destas palavras varia segundo uma multiplicidade de circunstâncias locais que somente a geografia pode esclarecer. É evidente que as tribos de pastores, obrigadas a alternar segundo as vicissitudes das estações os seus terrenos de pastagem, não saberiam ter sobre as questões de limites as idéias que uma valorização sedentária do solo

10 N.T.: "ville ou cité" no original em francês.

11 N.T.: "residência" aqui tem o sentido de lugar em que residiam, nos países na condição de protetorados, os altos funcionários (ou "résidents") designados pelo Estado "protetor". 
incutiu no espírito das sociedades agrícolas. Suponha um Estado que abrigue numa maioria de habitantes sedentários, uma proporção de elementos nômades, como acontece por exemplo no Egito. Ele estará apto a exercer influência, por ramificação, para além de suas fronteiras. Ou ainda, a existência de comunidades teocráticas, no seio de um Estado limitado, que poderá ser a causa de influências, ativas ou passivas, boas ou más, que se entrecruzam por sobre as fronteiras. Não será este o caso entre a Argélia e o Marrocos? Por fim, deve-se ter em conta o que destacarei no momento apropriado. Entre Estados pouco civilizados, não podem haver limites respondendo a uma simples linha ${ }^{12}$; a separação se expressa por uma zona de isolamento, semelhante àquelas que foram realizadas, por imitação, nos Confins militares que uma parte da Europa conheceu até nossos dias.

Isso me leva a uma questão de grande importância do ponto de vista do método. Os fatos da geografia política não são entidades fixas que basta registrar por uma simples constatação. Cidades e Estados representam formas que já evoluíram até chegar ao ponto em que as apreendemos, e talvez ainda estejam evoluindo. É preciso assim considerá-las como fatos em movimento.

Existe uma palavra da qual seria bom não abusar, mas que o Sr. Ratzel usa com razão ao falar dos Estados - a noção de organismo vivo. Esta expressão somente designa, por uma fórmula contundente, a lei de desenvolvimento que domina as relações do homem e do solo. Uma cidade, um Estado, no verdadeiro sentido da palavra, são expressões muito avançadas deste desenvolvimento; mas na sua origem existe um núcleo que lhes deu início, um ponto sólido ao redor do qual, por uma espécie de cristalização, agruparam-se as partes anexas. Neste sentido, parecem com seres vivos. Aqui intervêm plenamente as causas geográficas. E necessário, com efeito, localizar exatamente os fatos, estudá-los em sua ordem natural, isto é, do mais simples ao mais complexo, para discernir nestas combinações que chamamos de Estado, a força inicial que, com o tempo, serviu de centro de atração. Na origem do desenvolvimento político da île-deFrance, de Brandemburgo, do Grão-Ducado de Moscou, de Nova York, percebemos distintamente a ação de certos traços locais que, progressivamente, desencadearam outras causas.

Quem diz desenvolvimento diz ação e reação constantes. E no contato com forças adversas que os elementos da vida política se contratam e se tornam precisos. Assim se manifesta a necessidade de não estudar um Estado como um compartimento isolado, uma fração qualquer da superfície terrestre. Por sua origem, pela direção, pelas etapas e pelo termo sempre provisório de seu crescimento, ele se move num grupo cuja vida penetra também a sua. Acima dos Estados, há, dominando-os, o que poderíamos chamar de regiões políticas. A França, contígua a seis Estados diferentes, está geograficamente ligada à região política da Europa ocidental. A Inglaterra somente escapou desta região formando-se numa gigantesca Talassocracia através de uma combinação de ilhas, estreitos, cabos e pontos estratégicos para os quais o Oceano serve de união. A zona limítrofe das estepes constitui, na Ásia, um foco de ação política que envolve a Rússia, o Irã e a China, e ao contato do qual oscilações repetidas deram vantagem seja aos nômades, seja aos sedentários.

No Norte do Sudão se constituiu uma série de Estados resultantes das mesmas relações, e que se escalonam como colônias ao longo da margem saariana. Quando se considera, por outro lado, as sociedades políticas que se estabeleceram há muito tempo nos altos planaltos da América tropical, ainda se reconhece um grupo natural que convém não fragmentar, se quisermos

12 Para o desenvolvimento desta idéia, ver Ratzel, Politische Geographie, cap. XVIII, p. 457 e seguintes 
compreendê-lo.

Se procurarmos quais são os princípios motores do desenvolvimento das cidades e dos Estados, devemos olhar sobretudo para as mudanças que ocorrem nos meios de comunicação e transporte. Um historiador que tivesse como objeto seguir a marcha destas mudanças ao longo da história, não perderia o seu tempo. Geograficamente, palavras tais como a aldeia ${ }^{13}$ da antiga Grécia ou o nomos do velho Egito expressam grupos de princípio, restritos, confusos em seus movimentos: a possessão dos rios ou do mar é então preponderante para permitir aos ribeirinhos, de certo modo, evitar o jugo das condições locais e ascender à forma de cités ou de Impérios. Mais tarde, a construção de estradas acompanha toda grande formação de Estados. Foi por uma rede de vias que Roma se apoderou do mundo mediterrâneo; este sistema coordenado de comunicações diretas e seguras foi uma novidade que modificou toda a economia de relações. A posição das cidades, sua importância recíproca e as próprias dimensões dos impérios se estabelecem em harmonia com um certo estado dos meios de comunicação e de transporte. Ao surgir uma destas revoluções que alteram profundamente as relações de distância, os fatos por si mesmos se põem de novo em movimento e as causas de agrupamentos trabalham sobre novas bases. Produz-se algo semelhante à renovação de atividade que atinge um rio quando alguma modificação terrestre provoca o aumento de seu declive.

É o que acontece hoje em dia: o vapor revolucionou as distâncias, e nisso nossa época aparece em primeiro lugar como criadora de fenômenos no ramo da geografia política. Ela permite observar ao vivo a evolução dos fatos. A rede das cidades estava lentamente composta em harmonia com os meios de comunicação de outrora: os de hoje, pela supressão de etapas que se tornaram sem objeto e pela acumulação dos recursos que eles concentram em alguns pontos, presidem um novo modo de agrupamento das populações. Nos países novos, a relação entre as estradas de ferro e as cidades é direta, surpreendente. Por operar em condições mais complexas, nem por isso o princípio de mudança surge com menos intensidade na velha Europa. Limitemonos a comparar as cifras de 4 milhões e meio [de habitantes] de Londres, de 2 milhões e meio de Paris, de 1.600 mil de Berlim, de 1.500 mil de Viena, àquelas do início do século.

Aplicado à navegação, o vapor aumenta os grandes emporia. Os pequenos portos, aos quais se acomodava a lentidão do comércio do passado, perdem hoje a sua razão de ser. Também neste caso é introduzido um princípio novo de seleção no desenvolvimento das cidades. E vemos coexistirem organismos de onde a vida se retira com outros para os quais ela aflui.

$\mathrm{Na}$ concorrência entre os Estados, a extensão ${ }^{14}$ adquire uma importância nunca vista. Depois de ter sido por muito tempo um obstáculo, o espaço está se tornando uma força. $\mathrm{O}$ passado sem dúvida já havia conhecido impérios « nos quais o sol nunca se punha », e não é tão antigo o fato de um império se formar indo do Báltico ao Pacífico, igual, como dizia Humboldt, à superfície visível da Lua. Mas estas aglomerações eram massas constrangidas por seu próprio peso. Mais ou menos rapidamente, hoje, a vida aí se insinua, penetrando sob a forma de locomotivas ou barcos a vapor ${ }^{15}$.

No ponto que alcançaram hoje os conhecimentos geográficos, é interessante para a geografia política fazer o inventário do rico material de fatos que existe a sua disposição. Às vezes parece que ela ignora sua própria riqueza. Ela deve se esforçar em trabalhá-las, tornando-se uma ciência que analisa, classifica e compara, pois a cartografia, por mais variados que sejam ou

13 N.T.: Aqui aparece o termo "bourgade" em francês entre parênteses, após a palavra no alfabeto original grego.

14 N.T.: "étendue", em francês, que pode também ser traduzido por "extenso".

15 N.T.: em inglês no original: "steamers" (barcos a vapor). 
que possam vir a ser seus meios de expressão, não será suficiente para a explicação dos fatos. Esses nomes reunidos, essas linhas de demarcação traçadas sobre uma folha de papel, às vezes encobrem tamanhas diferenças que somente uma interpretação atenta dos fatos que elas expressam pode lhes dar visibilidade.

Na mobilidade perpétua das influências que se intercambiam entre a natureza e o homem, seria sem dúvida uma ambição prematura querer formular leis. Mas parece claro que certos princípios de método já estão se revelando. Se esta apreciação, por mais insuficiente que seja, conseguir despertar esta idéia nos leitores, gostaria que ela se tornasse, para eles, um motivo para se reportar aos escritos do Sr. Ratzel ${ }^{16}$. Eles encontrarão aí, com todos os desdobramentos que comporta, uma concepção da geografia política que responde, em suma, ao presente estado da ciência.

Devemos almejar que a seiva que hoje anima outros ramos da geografia, comece de novo a atingir também esta: «Todo o pensamento do homem moderno, diz o Sr. Ratzel, já adquiriu uma marca mais geográfica, no sentido de uma localização mais precisa das idéias, de uma tendência mais freqüente em estabelecer uma conexão entre elas e os lugares e espaços da Terra ${ }^{17}$.» Esta apreciação para alguns pode parecer lisonjeira demais, mas não saberíamos definir melhor o serviço que, entre todos os ramos da geografia, este que trata do homem está particularmente designado a prestar.

16 Permitam-me indicar particularmente o segundo volume da Anthropogéographie, o segundo volume (2ª edição) dos Etats-Unis d'Amérique, e a Géographie politique.

17 Anthropogéographie, 2a parte, capítulo III, p. 57. 